\title{
Success rate of treating acromegaly at national hospital of Sri Lanka
}

\author{
S Pathmanathan ${ }^{1}$, M Saranapala, N P Somasundaram ${ }^{2}$ \\ Sri Lanka Journal of Diabetes, Endocrinology and Metabolism 2015; 5: 69-74
}

\begin{abstract}
Introduction: Pituitary surgery, radiotherapy and medical therapy with dopamine agonists (DA), somatostatin analogues (SA) and growth hormone receptor agonists (GHRA) are the main treatment modalities that are recommended for treating acromegaly. Most of these treatment modalities are too expensive or not available in most of the resource settings like ours. The objectives of this study were to describe the demographic factors, presentation and comorbidities in acromegaly patients and to analyze the outcome of the treatment modalities used in our clinical setting, which include remission, recurrence and mortality among patients with acromegaly.
\end{abstract}

Materials and methods: This was a descriptive cross sectional study conducted among 72 acromegaly patients attending endocrinology and pituitary clinics at national hospital of Sri Lanka between January 2012 and June 2013. Pituitary adenomas were classified based on Hardy's classification. A remission criteria of nadir growth hormone level $<1 \mathrm{mu} / \mathrm{l}$ after oral glucose tolerance test (OGTT) or less than 5 $\mathrm{mu} / \mathrm{l}$ in a five point growth hormone $(\mathrm{GH})$ day curve was used.

Results: $54.1 \%$ of the patients were females. The mean age of the patients at the time of presentation was $39.52(\mathrm{SD} \pm 12.8)$ years and the mean duration of symptoms on presentation was 3.28 years $(\mathrm{SD} \pm$ 2.7). The commonest presentations were the changes in facial appearances and the increase in shoes and ring sizes (88\%). $81.8 \%$ had tumour grade II and above. $14.2 \%$ had prolactin co-secretion with GH. $86.1 \%$ underwent transsphe noidal surgery (TSS). $37.5 \%$ of patients with grade I tumour and $33.3 \%$ of patients with grade II tumour achieved remission following TSS. None of the patients with tumour grade III or above achieved remission following (TSS). In our series, overall remission was $22.5 \%$. External beam radiotherapy (EBRT) was effective in $20 \%$ in achieving remission. Medical therapy (either cabergoline or bromocriptine) as bridging /primary therapy achieved remission in only $20.8 \%$. Irrespective of the mode of treatment, no recurrence was noted in the patients who achieved remission. The mortality in this case series was $2.7 \%$.

Conclusions: Although the grade III and IV tumours has limited success, TSS remains the treatment of choice in acromegaly. EBRT and medical therapy with dopamine agonist have limited efficacy. Most of the other recommended options are very costly or unavailable in Sri Lanka. This study further highlights the importance of establishing specialist pituitary surgery services and introducing modern medical therapy to improve patient outcome.

Key words: acromegaly, dopamine agonists, radiotherapy, transsphenoidal surgery

\section{Introduction}

Acromegaly is characterized by increased and unregulated growth hormone $(\mathrm{GH})$ production usually caused by a GH-secreting pituitary tumor. It's a rare, insidious and potentially life-threatening condition. However, effective control of acromegaly has been shown to improve mortality and morbidity in patients $(1,2)$. Studies on acromegaly estimate an all-cause mortality rate of at least twice that of the normal population. The major sequelae of acromegaly include cardiorespiratory and cerebrovascular diseases, diabetes and neoplasia; particularly colon cancer (2). Although this an important clinical entity that needs proper interventions, there are no published data on management of acromegaly in Sri Lankan patients.

Treatment of acromegaly is complex and is expensive. Biochemical cure or adequate control is defined as a glucose-suppressed GH concentration of less than 2ng/ $\mathrm{ml}$ by radioimmunoassay ( $1 \mathrm{mcg} / 1$ by IRMA) and normalization of the serum IGF-I concentration $(3,4)$. No

${ }^{1}$ National Hospital of Sri Lanka, Colombo. 
single modality of treatment has consistently achieved the above levels (4). A multimodality approach is usually required, surgery as the first line of treatment followed by medical therapy, for residual disease. Radiation treatment is generally reserved for refractory cases.

TSS is the preferred treatment of choice. SA and DA and GHRA are the mainstays of medical treatment and are generally used if primary surgery alone does not result in complete remission. SAS and GHRA's are currently not used in resource limited health care settings because of their cost, instead DA, which have limited effectiveness are the mainstay in the medical management. Bromocriptine can reduce the circulating $\mathrm{GH}$ level to less than $5 \mathrm{ng} / \mathrm{ml}$ in only $20 \%$ of patients and can normalize the IGF-I concentration in $10 \%$ of patients. Shrinkage in tumor size is also observed in fewer than $20 \%$ of patients. Cabergoline, another DA, has fared somewhat better with response rates of upto $46 \%$ (4).

Radiation treatment takes time to reduce or normalize GH/IGF-I levels. About $60 \%$ of patients have a GH concentration of less than $5 \mathrm{ng} / \mathrm{mL} 10$ years after radiotherapy. Panhypopituitarism develop in a similar percentage as a result of treatment is the main drawback of this treatment modality. Because of the disappointing results and adverse effects, radiotherapy is used as an adjuvant for large invasive tumors and when surgery is contraindicated (4).

\section{Methods}

This retrospective descriptive study was conducted among 72 patients diagnosed with GH excess (acromegaly and gigantism) attending the endocrine and pituitary clinic at national hospital of Sri Lanka. The old patients who were already been followed up in these clinics as well as the new patients who were enrolled during the study period were included for the study. Informed written consent was obtained from all patients. Study was carried out between January 2012 and June 2013.

\section{Management protocol adopted}

$\mathrm{GH}$ excess was diagnosed when there was failure of suppression of $\mathrm{GH}(<1 \mathrm{mU} / \mathrm{L})$ following a $75 \mathrm{~g}$ glucose load. Serum insulin like growth factor-1 IGF-I concentration was performed when patients were able to afford the out of pocket cost of test. All the patients underwent pretreatment lab assessment of 9am cortisol, free T4, prolactin, Luteinizing hormone (LH) and follicle stimulating hormone (FSH). Details of these associated pituitary hormones were recorded to identify associated hormonal abnormalities. If serum prolactin value were above 3000 $\mathrm{mu} / \mathrm{l}$, diagnosis of prolactin co-secretion with $\mathrm{GH}$ was made and further dilution studies were performed.
All the patients underwent magnetic resonance imaging (MRI) scan of the pituitary as the primary mode of imaging. Pituitary adenomas were classified based on Hardy's classifications (Table 1). Grade I tumours are also called as microadenomas ( which are grade II and above, are classified as macroadenomas (size $10 \mathrm{~mm}$ and above). In patients with normal MRI on diagnosis additional imaging of the chest and abdomen were performed to look for extra pituitary source.

\section{Table 1. Neuro-anatomical classification of pituitary} adenomas (based on Hardy, 1969)

\begin{tabular}{|c|c|c|c|}
\hline Grade & Size & Location & $\begin{array}{l}\text { Bony } \\
\text { changes }\end{array}$ \\
\hline I & $<10 \mathrm{~mm}$ & Intrapituitary & None \\
\hline II & $>10 \mathrm{~mm}$ & $\begin{array}{l}\text { Intrasellar or } \\
\text { suprasellar expansion, } \\
\text { no invasion }\end{array}$ & $\begin{array}{l}\text { Sellar } \\
\text { expansion }\end{array}$ \\
\hline III & Any & $\begin{array}{l}\text { Intrasellar or } \\
\text { suprasellar expansion, } \\
\text { local invasion }\end{array}$ & $\begin{array}{l}\text { Sellar } \\
\text { erosion }\end{array}$ \\
\hline IV & $>10 \mathrm{~mm}$ & $\begin{array}{l}\text { Suprasellar expansion, } \\
\text { invasion of extrasellar } \\
\text { structures }\end{array}$ & $\begin{array}{l}\text { Bone } \\
\text { invasion }\end{array}$ \\
\hline
\end{tabular}

All patients who were diagnosed of having pituitary adenomas were referred for surgery except the patients who refused surgical intervention and the patients who were not fit to undergo surgery. Where surgery was not possible, external beam radiotherapy (EBRT) and/or medical therapy was considered. Patients who were diagnosed to have extra pituitary source of $\mathrm{GH}$ excess were managed with medical therapy.

Five point growth hormone day curve and pituitary functions were repeated post-surgery and after EBRT. Cure or adequate control was defined, as a mean $\mathrm{GH}$ concentration less than $5 \mathrm{mu} / \mathrm{l}$ in a five point GH Day curve. Repeat imaging was done at 3 months and 1 year post operatively and frequency of further imaging was decided on the findings of these post-operative images. Patients who had significant operable residual lesion in the MRI scan done 3 months postoperatively were referred for repeat surgery followed by EBRT. In cases where repeat surgery was not possible, the patients were referred for EBRT. In patients needing medical therapy, cabergoline or bromocriptine was used as the bridging therapy until adequate control was achieved.

Patients who were above 40 years of age were referred for colonoscopy to exclude colonic polys. Echocardiogram 
was performed in these patients in order to look for associated cardiac conditions and in patients who were on cabergoline to exclude associated valvular lesions.

Data was collected from case notes and by interviewing the patients. Data included symptoms and signs, imaging and laboratory results, operative findings, clinical outcome, GH values following OGTT and IGF-1 levels. It also included details of radiotherapy and medical therapy given. Data on cure, remission, recurrence and mortality was also collected for analysis.

\section{Results}

Among the 72 patients with GH excess, 38 (54.1\%) were females. The mean age of patients was $46(\mathrm{SD} \pm 12.6)$ years while the mean age of the patients at the time of presentation was $39.52(\mathrm{SD} \pm 12.8)$ years. The mean duration of symptoms on presentation was 3.28 years $(\mathrm{SD} \pm 2.7)$. The mean follow-up was $5.2(\mathrm{SD} \pm 4.9$ ) years.

Increased sweating, headache, change in facial appearance and increasing shoes and ring sizes were the commonest symptoms on presentation (Table 2).

The basal mean plasma GH was 62.1mU/L $(\mathrm{SD} \pm 55.9)$ and mean IGF-1 was $605.8(\mathrm{SD} \pm 238)$.

Table 2. Frequencies of symptoms on presentation

\begin{tabular}{|c|c|}
\hline Symptoms & $\begin{array}{l}\text { No of patients } \\
\text { diagnosed }\end{array}$ \\
\hline Change in facial appearance & $64(88 \%)$ \\
\hline Change in ring and shoe sizes & $64(88 \%)$ \\
\hline Increased sweating & $59(81.9 \%)$ \\
\hline Headache & $49(68.1 \%)$ \\
\hline Visual field involvement & $31(43.1 \%)$ \\
\hline Diabetes & $28(38.8 \%)$ \\
\hline Hypertension & $22(30.5 \%)$ \\
\hline Hypopituitarism & $16(22.2 \%)$ \\
\hline Delayed puberty & $4(5.5 \%)$ \\
\hline Kyphosis & $3(4.1 \%)$ \\
\hline Pituitary apoplexy & $1(1.3 \%)$ \\
\hline $\begin{array}{l}\text { Bony lumps (Associated } \\
\text { with Mccune Albright Syndrome) }\end{array}$ & $1(1.3 \%)$ \\
\hline $\begin{array}{l}\text { Symptoms suggestive of } \\
\text { pheochromocytoma (Adrenal lesion } \\
\text { producing catecholamines / GH) }\end{array}$ & $1(1.3 \%)$ \\
\hline
\end{tabular}

Pituitary imaging was available for 55 patients. Out of these 55 patients, 8 patients $(14.5 \%)$ had Grade I tumour (microadenomas), while 45 patients $(81.8 \%)$ were diagnosed with a grade II and above (macroadenomas). In this series, two patients $(3.6 \%)$ had normal pituitary MRI (Table 3)

Table 3. Neuroanatomical classifications of pituitary adenomas (based on Hardy, 1969)

\begin{tabular}{lll}
\hline Size & Grade & No of patients $(n=53)$ \\
\hline Microadenoma & I & $08(15 \%)$ \\
Macroadenoma & II & $16(30.1 \%)$ \\
& III & $27(50.9 \%)$ \\
& IV & $02(3.77 \%)$ \\
\hline
\end{tabular}

In our series, $85 \%$ had macroadenomas and $14.2 \%$ had prolactin co-secretion with $\mathrm{GH}$.

\section{Outcome of management of acromegaly patients}

TSS was performed in 62 patients while 3 patients underwent craniotomy. Two patients were lost for followup while awaiting surgery. One patient refused surgery and was started on medical treatment. One patient who was diagnosed as Mccune Albright syndrome did not undergo surgery and was started on medical therapy. One patient had an adrenal lesion, which was co-secreting catecholamines and GH. This patient was diagnosed to have a growth hormone releasing hormone (GHRH) producing adrenal tumour and underwent right sided adrenelectomy, which resulted in cure of acromegaly. Two patients who did not have tumours in pituitary imaging did not undergo surgery. These two patients underwent further imaging for the source of GH. As all the images were negative they were started on medical treatment. In total, surgery could not be done in six patients $(8.3 \%)$ either as the tumour was not located or due to patient refusal.

\section{Outcome of TSS}

Sixty two patients $(86.1 \%)$ underwent TSS. Twenty six patients had tumour grade III and above (macroadenomas with suprasellar extension), while 15 patients had grade II tumours (macroadenomas without suprasellar extension) and 8 patients had grade I tumour (microadenomas). Thirteen patients did not have details about the tumour grade preoperatively. Remission was achieved in $37.5 \%$ of patients with grade I tumour and $33.3 \%$ of patients with grade II tumour. No recurrence was noted in these patients. None of the patients with tumour grade III or above achieved remission following TSS. The remission rate in patients with macroadenomas (grade II and above) was $12.1 \%$. In our series, overall remission 
rate was $22.5 \%$. Five patients who did not achieve remission had no demonstrable residual tumour on postsurgery MRI and received EBRT. Add on medical therapy with DA was initiated in 49 patients who failed to go into remission after surgery. Out of these 49 patients, 9 patients underwent repeat surgery as there was significant residual tumour found in the three months post-surgery MRI. Currently, 4 patients are awaiting repeat surgery while 4 patients who refused repeat surgery are awaiting radiotherapy. In our study population 28 patients received EBRT while, 4 patients who have undergone TSS are currently awaiting 3 months post-surgery assessment to define cure.

\section{Outcome of trans-cranial surgery}

In our series, three patients $(4.1 \%)$ underwent transcranial surgery due to the tumour size, extent and preference of the neurosurgeon. These three patients were not cured following surgery and were started on medical therapy and underwent EBRT.

\section{Outcome of EBRT}

In our study, 30 patients received EBRT either as primary therapy or as adjuvant therapy following surgery while 4 patients are currently awaiting EBRT. 6 patients who refused EBRT were started on medical therapy. Out of the $6(20 \%)$ patients who were not cured previously had normalization their GH levels following EBRT. However, EBRT was ineffective in $24(80 \%)$ patients in achieving remission in five years.

\section{Outcome of medical therapy (cabergoline/bromocriptine)}

Medical therapy was started as primary therapy (cabergoline / bromocriptine) in 4 patients ( 1 patient who refused either surgery or EBRT, 2 patients who did have a tumour on imaging and 1 patients who was diagnosed as having Mccune Albright syndrome). Out of these 4 patients, 3 of them did not achieve remission with medical therapy. 43 patients were started on medical therapy as a bridging therapy. Clinical cure was achieved in 9 patients. Thus medical therapy, as bridging or primary therapy, achieved remission in only $20.8 \%$ of the patients. $\mathrm{GH}$ reduction was more with cabergoline and better tolerated than with bromocriptine.

\section{Mortality}

The mortality in this case series was two out of 72 $(2.7 \%)$. Both died due to cardiac failure.

\section{Discussion}

The outcome of patients with acromegaly is determined not only by the efficacy of individual treatment options but also depends on the availability of the treatment options. In resource constrained health systems, the expertise available and the scarcity of the treatment modalities could significantly affect the final outcome. Our study population showed a female predominance, which was consistent with other studies from rest of the world $(5,7)$. Our patients were younger (41-50 years) (39.52, $\mathrm{SD} \pm 12.8)$ compared to those reported in previous series from other countries (5-8) and the duration of symptoms were shorter ( 3.28 years, $\mathrm{SD} \pm 2.7)$ compared to 5-8 years $(6,8)$ in the patient populations described in most of the studies.

Acromegaly is well-known for its long delay from onset of symptoms to diagnosis $(9,11)$. It has a slowly progressive nature, which goes un-noticed until patient visits the doctor for other illnesses or for co-morbidities associated with acromegaly. Therefore, most of these patients have visible facial and extremities changes by the time of their diagnosis. $88 \%$ of our study population had facial and acral changes at the time of diagnosis. Reid et al (11), in their study noticed that the clinical characteristics at diagnosis of patients with acromegaly has not changed from 1981-2006 suggesting that clinical recognition of acromegaly has not significantly improved over the last 25 years.

In our study population, $81.8 \%$ was diagnosed with grade II tumour and above (macro adenomas), which was in concordance with the size of the pituitary tumour reported in most series $(6,10,16,18)$. TSS is the treatment of choice in acromegaly and in our series $86.1 \%$ underwent TSS. Overall remission rate after TSS was $22.5 \%$ and this is well below the rates reported in other series (42\%-75\%) (Table 4). In our study, group of $37.5 \%$ patients with grade I tumour (microadenoma) and $33.3 \%$ of patients with grade II tumour achieved remission while none of the patients with tumour grade III or above achieved remission following TSS. The remission rate in patients with macroadenomas (grade II and above) was $12.1 \%$. Compared to prestigious neurological centres in the developed world, the availability of expertise and limited resources seem to have influenced the outcomes of acromegaly in our series. Publications on outcome studies from countries with limited facilities are not widely available for comparison.

Wang et al. (19) observed that remission rates for acromegaly surgery improved following establishment of a specialist surgical service, with a reduction in surgeon numbers. According to their study, the overall surgical remission rate in 1998 was $27 \%$, which improved to $67 \%$ in 2012 after establishing a specialist pituitary surgery service with reduced surgeon numbers. There is also an operative learning curve for the surgeons and there has been an improvement in outcome after performing about 50 TSS (14). This further highlights the benefits of establishing specialist pituitary surgery services in resource poor settings. 
Radiotherapy (RT) is an effective, low-cost and reasonably safe mean of controlling the disease activity in acromegaly. Conventional RT is an additional treatment option for patients who have persistent disease activity despite pituitary surgery. It is particularly useful in resource poor settings where newer medical options like SA and GHRA are not readily available. The effect of radiotherapy is delayed and normalization of IGF1 has been reported, in up to $60-90 \%$ of patients, $10-15$ years after conventional fractionated radiotherapy (26-29). In our study, $20 \%$ of the patients who received EBRT normalized their GH levels after a median follow-up period of 5.2 years. This response rate is lower than those reported from other large cohorts with similar observation periods (27), but similar to the response rates of Minniti et al (29) and Gutt et al (28). However, normalization of elevated hormone levels may take up to 15 years $(4,5)$ long follow-up periods are required to assess the outcome of pituitary radiotherapy.

Although DA are widely used, SA are considered as the first-line of treatment in the medical management of acromegaly. DA, cabergoline has greater efficacy and tolerability compared to bromocriptine that has shown to normalize GH/IGF-I levels in only around $10 \%$ of cases $(1,2,4,5)$ whereas cabergoline has better response rates of $46 \%$ (4). In our study, medical therapy with DA either as primary or bridging therapy achieved remission in only $20.8 \%$ of patients. However, in those whom there is response to therapy, DA become a cheaper alternative. In a study by Moyes et al (30), carbegoline demonstrated complete biochemical remission in $27 \%$. Similarly a study from India reports a $25 \%$ efficacy of cabergoline (alone/ add-on) in achieving remission (31). GH reduction and tolerability was better in patients who were on cabergoline than the patients who were on bromocriptine (31), which was similar to results published elsewhere.

\section{Conclusion}

TSS remains the treatment of choice in acromegaly, though in grade III and IV tumours the success was limited. As most of the recommended options are very costly or unavailable in Sri Lanka, alternative treatment options generally used are EBRT or medical therapy (cabergoline/ bromocriptine) which have limited efficacy. Optimal treatment needs to be individualized depending on the efficacy, availability and affordability of treatment modalities. This study also highlights the importance of establishing specialist pituitary surgery services to improve outcomes.

\section{References}

1. Shlomo Melmed, M.B. Acromegaly. New England Journal of Medicine 2006 ; 355: 2558-73.

2. Giustina A, Chanson P, Bronstein MD, et al. A consensus on criteria for cure of acromegaly. Journal of Clinical Endocrinology and Metabolism 2010; 95(7):3141-8.
3. Bates AS, Van't Hoff W, Jones JM, et al. An audit of outcome of treatment in acromegaly. Quarterly Journal of Medicine 1993; 86(5): 293-9.

4. Katznelson L, Atkinson JL, Cook DM, et al. American Association of Clinical Endocrinologists Medical Guidelines for Clinical Practice for the Diagnosis and Treatment of Acromegaly-2011 update: executive summary. Endocrine Practise 2011; 17(4): 636-46.

5. Melmed S, Colao A, Barkan A, Molitch M, Grossman AB, Kleinberg D,Clemmons D, Chanson P, Laws E,Schlechte Jet al. Guidelines for acromegaly management: an update. Journal of Clinical Endocrinology and Metabolism 2009; 94: 1509-17.

6. Kwon O, Song YD, Kim SY, Lee EJ. Rare Disease Study Group; Science and Research Committee; Korean Endocrine Society. Nationwide survey of acromegaly in South Korea. Clinical Endocrinology 2013; 78(4): 577-85.

7. Fukuda I, Hizuka N, Murakami Y, Itoh E, Yasumoto K, Sata A, Takano K. Clinical features and therapeutic outcomes of 65 patients with acromegaly at Tokyo Women's Medical University. Internal Medicine 2001; 40(10): 987-92.

8. Schöfl C, Franz H, Grussendorf M, Honegger J, JaurschHancke C, Mayr B, Schopohl J; participants of the German Acromegaly Register.Long-term outcome in patients with acromegaly: analysis of 1344 patients from the German Acromegaly Register. European Journal of Endocrinology 2013; 168(1): 39-47.

9. Mestron A, Webb SM, Astorga R, Benito P, Catala M, Gaztambide S, Gomez JM, Halperin I, Lucas-Morante T, Moreno B, Obiols G, de Pablos P, Paramo C, Pico A, Torres E, Varela C, Vazquez JA, Zamora J, Albareda M, Gilabert M. Epidemiology, clinical characteristics, outcome, morbidity and mortality in acromegalybased on the Spanish Acromegaly Registry (Registro Espanol de Acromegalia, REA). European Journal of Endocrinology 2004; 151(4): 439-46.

10. Dusek T, Kastelan D, Melada A, Baretic M, Skoric Polovina T, Perkovic Z, Giljevic Z, Jelcic J, Paladino J, Aganovic I, Korsic M. Clinical features and therapeutic outcomes of patients with acromegaly: single-center experience. Journal of Endocrinological Investigations 2011; 34(11): 382-5.

11. Reid TJ, Post KD, Bruce JN, Nabi Kanibir M, Reyes-Vidal CM, Freda PU. Features at diagnosis of 324 patients with acromegaly did not change from 1981 to 2006: acromegaly remains under-recognized and under-diagnosed. Clinical Endocrinology (Oxf) 2010; 72(2): 203-8.

12. Fukuda I, Hizuka N, Muraoka T, Kurimoto M, Yamakado Y, Takano K, Ichihara A. Clinical features and therapeutic outcomes of acromegaly during the recent 10 years in a single institution in Japan. Pituitary 2014; 17(1): 90-5.

13. Margreet Albertina E. M. Wagenmakers, Romana T. NeteaMaier, Ad R. M. M. Hermus Results of endoscopic transsphenoidal pituitary surgery in 40 patients with a growth hormone-secreting macroadenoma Acta Neurochirurgica (Wien) 2011; 153(7): 1391-9.

14. Leach P, Abou-Zeid AH, Kearney T, Davis J, Trainer PJ, Gnanalingham KK. Endoscopic transsphenoidal pituitary surgery: evidence of an operative learning curve. Neurosurgery 2010; 67(5): 1205-12.

15. Kim MS, Jang HD, Kim OL Surgical results of growth hormone-secreting pituitary adenoma. Journal of Korean Neurosurgical Society 2009; 45: 271-4. 
16. Sheaves R1, Jenkins P, Blackburn P, Huneidi AH, Afshar F, Medbak S, Grossman AB, Besser GM, Wass JA.Outcome of transsphenoidal surgery for acromegaly using strict criteria for surgicalcure. Clinical Endocrinology (Oxf) 1996; 45(4): 407-13.

17. Gondim JA, Almeida JP, de Albuquerque LAF, Gomes E, Schops M, Ferraz T Pure endoscopic transsphenoidal surgery for treatment of acromegaly: results of 67 cases treated in a pituitary center. Neurosurgical Focus 2010; 29: 7 .

18. Derya Burcu Hazer, Serhat I??k, Dilek Berker, Serdar Güler, Alper Gürlek, Ta?k?n Yücel, Mustafa Berker,Treatment of acromegaly by endoscopic transsphenoidal surgery: surgical experience in 214 cases and cure rates according to current consensus criteria. Journal of Neurosurgery 2013; 119(6): 1467-77.

19. Wang, YY, Higham C, Kearney T, Davis JRE, Trainer P and Gnanalingham KK. Acromegaly surgery in Manchester revisited - The impact of reducing surgeon numbers and the 2010 consensus guidelines for disease remission. Clinical Endocrinology 2012; 76: 399-406.

20. Nomikos P, Buchfelder M, Fahlbusch R The outcome of surgery in 668 patients with acromegaly using current criteria of biochemical 'cure.' European Journal of Endocrinology 2005; 152: 379-87.

21. John A. Jane, Jr., Robert M. Starke, Mohamed A. Elzoghby, Davis L. Reames, Spencer C. Payne, Michael O. Thorner, John C. Marshall, Edward R. Laws, Jr., and Mary Lee VanceEndoscopic Transsphenoidal Surgery for Acromegaly: Remission Using Modern Criteria, Complications, and Predictors of Outcome. Journal of Clinical Endocrinology and Metabolism 2011;96(9): 2732-40.

22. Campbell PG, Kenning E, Andrews DW, Yadla S, Rosen M, Evans JJ. Outcomes after a purely endoscopic transsphenoidal resection of growth hormone-secreting pituitary adenomas. Neurosurgical Focus 2010; 29: 5.

23. Trepp R ${ }^{1}$, Stettler C, Zwahlen M, Seiler R, Diem P, Christ ER.Treatment outcomes and mortality of 94 patients with acromegaly. Acta Neurochirurgica (Wien) 2005; 147(3): 243-51.

24. Ludecke DK, Abe T. Transsphenoidal microsurgery for newly diagnosed Acromegaly: a personal view after more than 1,000 operations. Neuroendocrinology 2006; 83: $230-9$.

25. Minniti G1, Jaffrain-Rea ML, Esposito V, Santoro A, Tamburrano G, Cantore G. Evolving criteria for postoperative biochemical remission of acromegaly: can we achieve a definitive cure? An audit of surgical results on a large series and a review of the literature. Endocrine Related Cancer 2003; 10(4): 611-9.

26. González B1, Vargas G, Espinosa-de-los-Monteros AL, Sosa E, Mercado M Efficacy and safety of radiotherapy in acromegaly. Archives of Medical Research 2011; 42(1): 48-52.

27. Jenkins PJ, Bates P, Carson MN, Stewart PM and Wass JA. Conventional pituitary irradiation is effective in lowering serum growth hormone and insulin-like growth factor-I in patients with acromegaly. Journal of Clinical Endocrinology and Metabolism 2006; 91: 1239-45.

28. Gutt B, Hatzack C, Morrison K, Pöllinger B, Schopohl J Conventional pituitary irradiation is effective in normalising plasma IGF-I in patients with acromegaly. European Journal of Endocrinology 2001; 144(2): 109-16.

29. Minniti G, JaffrainRea ML, Osti M, Esposito V, Santoro A, Solda F, Gargiulo P, Tamburrano G and Enrici RM. The long-term efficacy of conventional radiotherapy in patients with GH-secreting pituitary adenomas. Clinical Endocrinology 2005; 62: 210-6.

30. Moyes VJ, Metcalfe1 KA and Drake WM, Clinical use of cabergoline as primary and adjunctive treatment for acromegaly. European Journal of Endocrinology 2008; 159: $541-5$.

31. Sanyal D, Raychaudhuri M. Outcome in acromegaly: A retrospective analysis. Indian Journal of Endocrinology and Metabolism 2012; 16: 291-3. 